Cadernos de Clio, Curitiba, n. ${ }^{\circ}$ 2, 2011

Nota de Pesquisa

\title{
Romance e ciência: a relação entre História e Literatura na sociedade oitocentista ${ }^{1}$
}

\author{
Pesquisa Coletiva PET-História ${ }^{2}$ \\ Lana Baroni ${ }^{3}$
}

A Literatura sempre esteve ligada à História. Desde a Antiguidade a História era pensada através de narrativas sobre sociedades e suas práticas, ainda que nesse momento a intenção não fosse problematizar os fatos, mas conhecê-los e passá-los para as sociedades futuras, em um processo de preservação e transmissão da memória. Em oposição à ligação entre essas duas áreas de conhecimento, passamos a notar que no século XIX houve um grande destaque além de críticas por parte da Literatura diante da História e de seu encaminhamento.

\footnotetext{
${ }^{1}$ Resultados de pesquisa apresentados nos eventos Diálogos do PET (maio/2011) e $19^{\circ}$ EVINCI (outubro/2011).

2 Alunos: Bárbara Zanirato, Davi Pradi, Eduardo Nogueira, Fernando Botton, Gabriela Larocca, Juliana Amorim, Lana Baroni, Luis Fernando Cavalheiro, Naiara Kranchenski, Nicolle Taner de Lima, Sergio Luiz Rabelo, Stella Castanharo, Vinicius Paludo. Tutoras: Ana Paula Vosne Martins (janeiro a setembro/2010) e Renata Senna Garaffoni (setembro a dezembro/2010).

${ }^{3} \mathrm{O}$ presente texto foi redigido pela bolsista para os eventos acima citados.
} 
Partindo desses pressupostos, a pesquisa coletiva do PETHistória desenvolvida ao longo do ano de 2010 tinha por tema a "História e Literatura: narrativas da ciência, da sociedade e da cultura oitocentista", e buscávamos em primeiro lugar estabelecer um diálogo entre essas duas grandes áreas, bem como através da análise de fontes, investigar as relações intertextuais entre as experiências histórico-culturais associadas ao conhecimento científico e à sua aplicabilidade através das narrativas literárias que trataram deste período, pautados pelo ideal de uma sociedade que podemos definir como nova, em função de percebermos mudanças sociais baseadas em novos usos da razão e da tecnologia, na normatização, no progresso e no que é possível chamarmos de uma nova humanidade.

Através desses elementos iniciais nossa pesquisa deu-se em dois momentos principais: discussões sobre a própria Literatura e seus elementos, bem como a compreensão da importância da Literatura para a prática da História; e posteriormente analisamos quatro obras de grande importância e destaque para o século XIX, pois problematizavam a sociedade, o indivíduo, a ciência e o progresso tecnológico.

Tendo em vista esses elementos, buscamos nesta síntese de nosso trabalho levantar pontos para a discussão do tema e 
desenvolver a ideia de romance e as características que permitiram nosso estudo, partindo da concepção de que o romance pode ser considerado como fonte histórica e um elemento essencial de uma sociedade específica, no caso a sociedade oitocentista, e em um segundo momento analisaremos as quatro obras discutidas em nossa pesquisa. São elas: Frankenstein de Mary Shelley, $O$ Médico e o Monstro de Robert Stevenson, A Volta ao mundo em 80 dias de Júlio Verne e Paris no século $X X$ de mesma autoria.

$\mathrm{Na}$ etapa inicial, consultamos textos de seis autores: Mimesis, de Eric Auerbach; $A$ ascensão do romance. Estudos sobre Defoe, Richardson e Fielding, de Ian Watt; Meta-História: a imaginação histórica do século XIX, de Hayden White; O ressurgimento da narrativa. Reflexões sobre uma velha história, de Lawrence Stone; Sobre História, de Eric Hobsbawm; e A microHistória e outros ensaios de Carlo Ginzburg.

Da análise destas obras pudemos compreender algumas condições que definem e diferem o romance moderno do século XVIII em relação às obras literárias anteriores e de que forma o romance é uma forma literária nova que se iniciou na Inglaterra setecentista. Para Ian Watt, existiram condições específicas da época que favoreceram o surgimento deste tipo de produção e o "realismo" é a principal característica que torna o romance uma novidade. $\mathrm{O}$ 
realismo desses romances é assim considerado pelo fato de retratarem as experiências "reais" dos personagens e pela maneira que ele as apresenta, por exemplo, em sua orientação individualista e inovadora. Segundo Watt, o romance do século XVIII se atém à experiência individual enfatizando o indivíduo e a experiência única. Este traço do romance, da rejeição dos valores universais e da ênfase nos particulares, se traduz, também, na criação de personagens e acontecimentos específicos e não abrangentes como anteriormente. Watt afirma que romancistas e filósofos da época "dedicaram ao indivíduo particular atenção do que este recebera até então" (WATT: 19) e afirma que a nomeação dos personagens dos romances com nomes próprios e verossímeis ao seu contexto de produção expressa uma identidade particular da personagem, que deve ser vista como uma pessoa singular.

Com relação às outras obras, analisamos essencialmente a escrita literária em suas estruturas linguísticas. No texto de Eric Auerbach, por exemplo, há uma apresentação da literatura épica e uma ênfase nas características próprias de sua narrativa e de seu enredo, exemplificadas com os relatos de Homero. Auerbach trata deste gênero textual como responsável por prender o leitor ou ouvinte através de seus elementos de tensão, das explicações sobre todos os elementos mencionados e na utilização de um presente 
espacial e temporal ao descrever e narrar os acontecimentos com o que o autor chama de uma "pretensão de verdade". Tais elementos são, em diversas ocasiões, encontrados nos textos de gênero romântico. Da mesma forma, no texto de Hayden White, há uma descrição de elementos dos quais se pode fazer uso em uma narrativa. Ao contrário de Auerbach, no entanto, que se foca em um estilo de narrativa, White busca ressaltar o uso das Figuras de Linguagem, se focando na análise estrutural e não em um estilo de escrita específico.

Por fim, apesar desta rápida síntese de contribuições da bibliografia selecionada à nossa pesquisa, devemos enfatizar que entendemos que a obra literária deve ser utilizada pelo historiador, não apenas pelo valor de sua narrativa, mas também pelas relações que esta mantém com sua época de produção e recepção e pelas influências de seu estilo em épocas subsequentes.

Partindo para o estudo das fontes literárias, fizemos uso de quatro obras escolhidas com um objetivo empírico, para problematizar as análises de cunho teórico discutidas pelo grupo.

A primeira obra selecionada foi Frankenstein, da autora inglesa Mary Shelley. O livro foi publicado no começo do século XIX, no ano de 1818 e é considerado um dos inauguradores do gênero de ficção científica. Seu enfoque é direcionado 
principalmente para as recentes descobertas da época na área da Eletricidade. Os estudos feitos no final do século XVIII pelo físico Luigi Galvani demonstraram uma resposta de corpos de animais mortos ao entrarem em contato com correntes elétricas. A partir dele, o físico Alessandro Volta passou a estudar o efeito da eletricidade nestes corpos. Estudiosos acreditam que Shelley se inspirou em Giovanni Aldini, sobrinho de Galvani, que tendo conhecimento das descobertas do tio, fazia apresentações de cadáveres se movimentando devido à eletricidade. Também o químico, Johann Dippel, alemão nascido no Castelo Frankenstein, fazia experiências em cadáveres nos séculos XVII e XVIII podendo ter influenciado Shelley na criação de seu conto. Tratando destas experiências, a autora de Frankenstein traz um discurso moral sobre a responsabilidade de um cientista perante seus estudos e o perigo contraposto com as maravilhas da ciência na relação com a criação da vida. Através de seu personagem principal, é perceptível uma posição rousseauniana da autora, uma vez que acredita que um indivíduo monstruoso é essencialmente bom, independente de sua forma física, mas que é corrompido por uma sociedade cruel.

A segunda obra analisada foi de Robert Louis Stevenson, $O$ médico e o monstro. Publicado em 1886, essa obra possui uma diferença temporal significativa da obra de Shelley. Comumente 
associado com os casos de dupla personalidade, o livro se foca nas descobertas médicas e no uso de drogas medicinais. A criação de uma poção que traria à consciência um lado malévolo faz o personagem de Dr. Jekyll retornar àquela que seria a natureza humana, má e sem remorso, mas que na figura do doutor se disciplina para se adaptar à sociedade londrina, tema que retoma as teorias freudianas que estavam sendo desenvolvidas contemporaneamente. $\mathrm{O}$ uso indiscriminado da poção torna a metamorfose do médico irreversível, necessitando do antídoto para preservar sua personalidade bondosa. Stevenson traz, assim como Shelley, uma visão negativa da ciência e de seus frutos, que muitas vezes não era tão perceptível, mas ainda assim danoso, e coloca a falta de controle ou a perda dele como o principal perigo das descobertas. Percebemos, portanto, que a literatura é o espaço da crítica a esta ciência que valoriza o progresso a qualquer custo, lembrando que esta crítica enfatiza o perigo do "não controle" sobre a experiência.

Em contraposição a estes autores, o francês, Julio Verne, expõe uma visão otimista do progresso científico. Em seu livro $A$ Volta ao Mundo em 80 dias, o autor faz uso de uma narração ritmada pelos aparelhos e meios de transporte dando uma impressão maquinária à leitura. O livro publicado em 1873 traz os meios de 
transporte como as principais invenções e a partir delas o autor constrói uma história que mostra como as transformações na tecnologia transformam a vida e a psicologia da população. Alguns temas tratados no livro são o encurtamento da relação do homem com o tempo e o espaço, através da velocidade dos meios de transportes e de comunicação; a estereotipação de culturas, presentes nos personagens principais que representam seus locais de origem; o controle dos eventos através da organização meticulosa e a previsibilidade, se não, a capacidade de contornar os mesmos e a apresentação de valores culturais locais do autor. Com seu enredo romântico e a exposição de inúmeras qualidades no progresso, Verne passa a ideia de uma tecnologia criada exclusivamente para o benefício da humanidade.

A última obra discutida por nosso grupo foi Paris no século $X X$, também de Júlio Verne. Essa obra diferente das demais não possui uma datação conhecida, mas pode-se imaginar que foi uma das primeiras obras escritas por Verne, ao destacarmos a presença de cartas entre o escritor e seu editor antecedendo a apresentação da obra em si na edição publicada pela editora Ática. Ao mesmo tempo, podemos notar o significativo destaque dado pelo autor a própria ficção científica, ao pensarmos que seu enredo envolve a Paris na 
metade do século XX produzida a partir de uma concepção e conhecimento de mundo do século XIX.

Em oposição ao $A$ Volta ao mundo em 80 dias, a visão de Verne se mostra pessimista, ao pensarmos que a presença da máquina no século XX suprimiria as artes. Mostra-se um constante choque entre a tecnologia e a própria literatura humanista, ao pensarmos que além de esta ser esquecida, ela seria abafada pela convivência e necessidade das máquinas. Ainda em relação à presença da literatura humanista na obra de Verne, cabe destacarmos que é uma visão estritamente romântica, pois as características desenvolvidas por Verne são de nostalgia e de recuperação de um passado brilhante nas artes.

Por fim, compete destacar que por mais que Júlio Verne faça uma projeção sobre o futuro, ele o faz pautado em suas observações sobre o próprio presente e os desenvolvimentos da sociedade em que vivia e nos apresenta, de forma espetacular, o constante conflito entre ciência e natureza, já muito acirrado numa sociedade pós-revolução industrial que já mostrava uma consolidação do saber, tão cara para a obra como para o próprio Verne. Sem esquecermos, contudo, que a concepção de ciência apresentada pelo escritor é definida a partir da ideia de ordem. 
Diversas questões práticas e teóricas sobre a história do romance devem ser levadas em consideração para compreendermos o diálogo entre a História e a Literatura, bem como sobre as obras literárias estudadas. As obras de Shelley e Stevenson, por exemplo, mesmo tendo sido escritas com certa distância temporal uma da outra, demonstram um discurso semelhante sobre as descobertas científicas que eram feitas em seus respectivos momentos. Frente a um discurso científico que enaltecia a quebra de barreiras e dos limites da humanidade, ambos preocupam-se, justamente, com esses limites. Ou seja, até mesmo o progresso, em doses desmedidas, seria prejudicial para a humanidade. Observamos, pois, que a preocupação com os limites do progresso cientifico não era uma questão isolada no século XIX.

Essa preocupação quanto aos limites da ciência, embora também presente em uma das obras de Verne, desaparece, ou pelo menos perde seu caráter crítico, nas suas obras seguintes. Paris no século $X X$ foi escrito anteriormente a $A$ Volta ao mundo em 80 dias, não tendo sido publicada no período por ser considerada muito sombria, característica essa que a torna bastante distinta das demais obras de Verne. A presença de discursos tão discrepantes a respeito do progresso produzidos pelo mesmo autor em tão pouco espaço de 
tempo nos mostra que as pessoas entendiam o progresso de forma não homogênea.

A preocupação em pensar o capitalismo também está presente. Em $A$ Volta ao mundo em 80 dias, o homem rico, regrado e de comportamento maquinal não expressa suas emoções ao ponto de colocar em dúvida a própria existência delas. A sua condição social abre as portas para a volta ao mundo, que termina com um final feliz. É o exato oposto do jovem romântico, apaixonado, desregrado, rebelde e pobre que padece sozinho no triste final de Paris no Século $X X$.

Percebemos, portanto, que a preocupação com o progresso científico é uma constante nas fontes analisadas, apesar de observarmos que os autores apresentem posições distintas. Acreditamos que, mais importante do que responder as questões com respostas fechadas é a reflexão sobre elas, desta forma o grupo pôde pensar o contexto estudado a partir das diversas visões individuais e coletivas expressas pelos autores, bem como inserir o debate sobre a produção de ficção científica no diálogo entre História e Literatura no entendimento da sociedade oitocentista. 


\section{Obras Literárias.}

SHELLEY, Mary Wollstonecraft. Frankenstein. São Paulo: Ática, 1998.

STEVENSON, Robert Louis. $O$ médico e o monstro. São Paulo: Ática, 1997.

VERNE, Julio. Paris no século XX. São Paulo: Editora Ática, 1995. VERNE, Julio. A Volta ao mundo em 80 dias. Rio de Janeiro: Ediouro, 1972.

\section{Bibliografia citada}

AUERBACH, Eric. Mimesis. São Paulo: Editora Perspectiva, 1971.

WATT, Ian. A ascensão do romance. Estudos sobre Defoe, Richardson e Fielding. São Paulo: Companhia das Letras, 1990.

WHITE, Hayden. Meta-História; a imaginação histórica do século XIX. São Paulo: EDUSP, 1995.

STONE, Lawrence. "O ressurgimento da narrativa. Reflexões sobre uma velha história". In Revista de História. $\mathrm{N}^{0} 2$ e $\mathrm{n}^{0} 3$. São Paulo: IFCH/UNICAMP, 1991.

HOBSBAWM, Eric. Sobre História. São Paulo: Companhia das Letras, 1998.

GINZBURG, Carlo. A micro-História e outros ensaios. Lisboa: DIFEL, 1991. 